\title{
Investigation of High-Velocity Projectile Penetrating Concrete Blocks Reinforced by Layers of High Toughness and Energy Absorption Materials
}

\author{
Aya Elhozayen ${ }^{a^{*}}$, Mohamed Y. Laissy ${ }^{b}$, Walid A. Attia ${ }^{c}$ \\ ${ }^{a}$ Faculty of Engineering, Civil Engineering Department, British University in Egypt, Cairo Governorate, Egypt. . \\ ${ }^{b}$ Department of Civil Engineering, College of Engineering, University of Prince Mugrin, Almadinah 41499, Saudi Arabia. \\ ${ }^{c}$ Structural Engineering Department, Faculty of Engineering, Cairo University, Egypt.
}

Received 09 March 2019; Accepted 20 June 2019

\begin{abstract}
Recently, the need to protect people and structures against attacks of terrorists are of a high increase. The main objective of this paper is to enhance the concrete resistance against ballistic impact of high velocity projectile by using different combination layers from different materials as reinforcement for concrete and investigate their effect on the penetration depth of projectile and the resulted damage of concrete. The investigation presents the development of a finite element accurate models using AUTODYN 3D. The Lagrangian formulation numerical techniques is used to model the projectile and concrete target. The investigated models are reinforced using different layers combinations of several materials such as ceramics, fiber composite, polymer and metal: $\left(\mathrm{AL}_{2} \mathrm{O}_{3}-99.7 \%\right.$ and Kevlar- epoxy, Teflon and aluminum alloy $6061-$ T6) .Those materials were chosen because of their high thermal shock resistance or their great capability in energy absorption. The main findings showed a significant enhancement in the reduction of penetration depth compared to the concrete resistance without reinforcement, which demonstrate the great performance of the used combinations in the shock wave propagation. Hence from the findings of this work we can say that the concrete reinforced by ceramics or aluminum alloy with fiber composite or polymer can be used for several applications as it represents a successful anti-penetration composite structure.
\end{abstract}

Keywords: Impact; Ballistic; Penetration; Concrete; Energy Absorption Materials.

\section{Introduction}

In civilian and military applications, the reinforced concrete has been used as an effective construction material for protective structures. The response of concrete structures to impact loading which results from terroristic attacks or highvelocity fragments due to accidental explosions and causes penetration and perforation that lead to failure of the structure, has become of great importance.

In the last decay, many empirical and numerical models as well as experimental studies were conducted to analyze the behavior of normal reinforced concrete subjected to impact loading with different ranges of velocities. Some of these empirical models were based on experiments and described the penetration depth, such as NDRC (1945) and ACE (1946) $[1,2]$. Others described the penetration resistance first, then used it to derive the penetration depth, such as the

* Corresponding author: aya.elhozayen@bue.edu.eg

http://dx.doi.org/10.28991/cej-2019-03091349

(C) 2019 by the authors. Licensee C.E.J, Tehran, Iran. This article is an open access article distributed under the terms and conditions of the Creative Commons Attribution (CC-BY) license (http://creativecommons.org/licenses/by/4.0/). 
penetration resistance model by Forrestal et al. (1994) that was based on shooting range test [3]. Some proposed computational models such as Johnson and Holmquist (1994) [4] who proposed an improved computational constitutive model for concrete, while Hwang et al. (2017) [5] proposed an energy-based model for local impact causing damage to concrete members, they focused on the resistant energy of the concrete target and kinetic energy of the projectile.

Experimental studies of plain and reinforced concrete targets subjected to impact loading were of great interest to researches such as Rajput et al. (2016) [6] who studied the influence of impact of rigid projectile on the ballistic performance of plain and reinforced concrete plates with different thickness; while Iqbal et al. (2016) [7] compared the effect of rigid projectile normal impact on ballistic limit and the damaged area of both plain and reinforced concrete. An investigation of a new type of composite concrete called corundum-rubble concrete (CRC) was done by Xue et al. (2017) [8], they compared the experiments results of CRC to reinforced concrete and they get much higher values for strength and hardness.

On the other hand, many numerical models were conducted to study and analyze the penetration and perforation of different elements of normal reinforced concrete, such as Smith and Cusatis [9] who studied the impact of a projectile on regular strength concrete (RSC) and high-strength concrete (HSC) using the Lattice Discrete Particle Model (LDPM). Jiriceka and Foglar [10] simulated the impact of regular and sub-caliber projectile on military bunkers (concrete blocks) using Autodyn 3D. Another numerical simulation was conducted using Autodyn by Tawadrous et al. (2016) [11], they modeled numerically the penetration of a high velocity projectile to concrete blocks reinforced by ceramic. Pereiraa, Pereira et al. (2018) [12] simulated the response of concrete subjected to ballistic impact with the effective rate dependent damage model, the model proposed could predict the failure modes observed during ballistic impact of concrete. Another numerical model of penetration and perforation of reinforced concrete targets subjected to a $25.4 \mathrm{~mm}$ steel projectile with varying striking velocity was simulated by Tham (2005) [13], he examined the influence of different constitutive models of concrete on the residual velocity of the projectile

Some researches merged between simulations and experiments to compare the results and validate the proposed numerical models; such as Almusallam et al. (2015) [14] who compared the effect of CFRP strengthening on the response of reinforced concrete slabs when modeled experimentally and numerically using LS-DYNA, the analysis was conducted under the impact of hemispherical steel projectile with varying velocity and the slabs. Pavlovic and Fragassa (2018) [15] evaluated the resistance level of reinforced concrete barriers subjected to ballistic impact, the study was done with explicit Finite Element (FE) simulations and the results were compared to experiments on similar RC barriers. Kamal and Eltehewy (2012) [16] investigated the penetration resistance of concrete blocks reinforced by different number of layers of woven wire steel mesh experimentally and numerically using a steel blunt-nose projectile with a diameter of $23 \mathrm{~mm}$ with striking velocity about $980 \mathrm{~m} / \mathrm{s}$, they found an overall reduction in penetration depth and damage of target when with using wire meshes as a reinforcement. Richardson et al. (2016) [17] compared the impact performance of fiber concrete to plain concrete to predict the damage of concrete in both cases, they simulated concrete slabs with finite element model and tested the use of two types of fibers as a reinforcement in concrete samples. Rajput and Iqbal [18] studied experimentally and numerically the ballistic impact behavior of reinforced and prestressed concrete targets, the experiment was carried out with different projectile striking velocities for three types of concrete, and the numerical investigation was modelled in finite element code ABAQUS. Kataoka et al. (2017) [19] studied the effect of moderate velocity impact on the failure characteristics of reinforced concrete slabs experimentally and numerically.

The main objective of this paper is to enhance the resistance of concrete blocks to impact of high velocity projectile and reduce its depth of penetration by using new combination layers of high toughness and energy absorption materials as reinforcement for concrete.

The main characteristics of materials adopted in ballistic protection design are: high bulk and shear moduli to prevent large deformations; high yielding stress to prevent failure; and high dynamic tensile stress to avoid material rupture when tensile waves appear. According to Lee and Yoo (2001) [20], ceramics satisfy the first two demands due to their high hardness that makes them capable to involve in ballistic protection but they are brittle, which makes for extensive fragmentation due to the tensile waves generated by the compressive waves reflected from the free surfaces; this is the reason why additional layers of composite material such as Kevlar epoxy or polymer such as Teflon are added as a backing plate to absorb the kinetic energy of the projectile and the ceramic during target penetrations, the high ductility of these materials combined with the high resistance of ceramics can make an efficient shield against. On the other hand, the 6061 aluminum alloy is chosen due to its good combination of strength, fatigue resistance and fracture toughness [21], which make it capable to resist the ballistic loading impact efficiently when combined by another material of good energy absorption like KE and Teflon.

\section{Theoretical Approach}

Impact is defined as a high force or shock applied over a very short time from a body to another one and inducing significant local contact deformation. From the perspective of conservation of energy, the kinetic energy of the impacting 
body will be partially converted to strain energy in the target and partly dissipated through friction and local plastic deformation, and the strain energy is radiated away as stress waves.

According to Christman and Gehring (1966) [22] , the penetration process due to high-velocity impact occurs in four phases:

1. Transient phase: it's when the projectile first contacts the target surface causing very short but intense pressure spike;

2. Primary penetration phase: it's the period during which the projectile acts as a propulsive force, transferring its kinetic energy to the target in a hydrodynamic manner;

3. Secondary penetration phase: it begins after the projectile is totally deformed and is not transferring any energy, the target deformation in this phase is caused by the energy density caused by the expanding shock wave;

4. Recovery phase: it's the period during which the crater recovers or contracts slightly.

The mechanism of penetration differs from one material to another, this section will discuss the penetration mechanism in concrete, metals, ceramics, polymers and composites.

During ballistic impact, a pressure wave is induced and expands radially through the concrete target, leading to interfering stress wave that results in rapid change in multiaxial stress states and strain rates of the target. Material local failure can occur in four main stages [23] as shown in Figure 1.

5. Penetration: the projectile tunneling into the target by a length called the penetration depth, formation a cone-like crack under the projectile.

6. Spalling and scabbing: the target material ejecting from the front and rear faces.

7. Perforation: the projectile passaging completely through the target with or without a residual velocity.

8. Recovery phase: it's the period during which the crater recovers or contracts slightly.
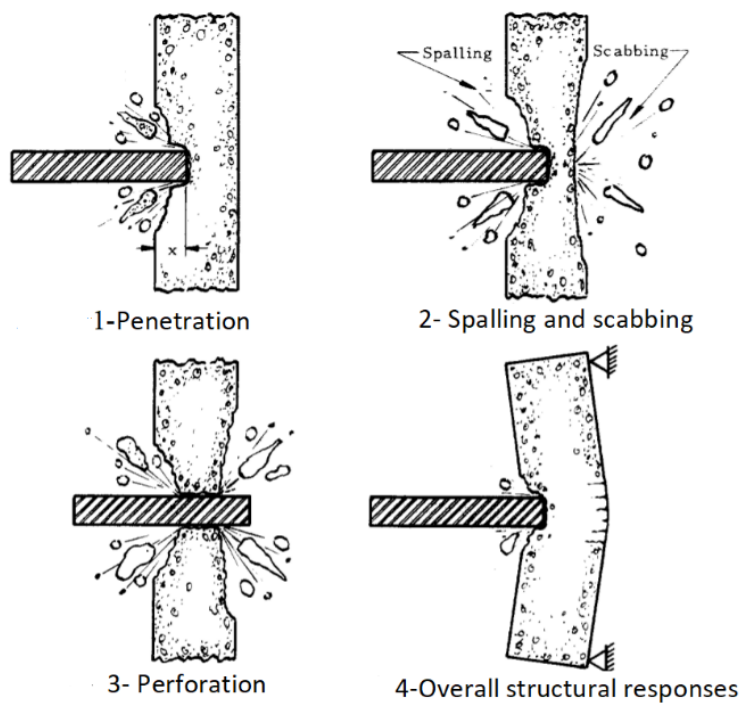

Figure 1. Projectile impact main stages [23]

For metals, the damage caused by a high velocity impact is complex and results from five failure modes that operate at once [24]: 1) adiabatic shear , 2) strain localization followed by brittle cracks, 3) ductile tensile failure, 4) plastic flow caused by the lines deviated from horizontal, 5) pressure causing polymorphic phase change.

Ceramics exposed to high velocity impact can show several damage mechanisms including shear localization; solidstate amorphization; dislocation activity; twinning; stacking faults; and phase transformations. Macro- and microcracking are usually occurred as well as ring, radial and cone cracks that extend into the target and form divergent angles from the impact point. The projectile with a sufficient kinetic energy can penetrate into ceramic targets and cause the failure of damage zone so that the material is pushed away from the projectile path [25].

Polymers are usually used as backing plates for laminated ceramic in armor systems. The penetration of polymer plates occurs by elastic dishing, petalling, cone cracking, and plugging, the projectile, pushing a cylinder of material ahead, reaches the rear surface and perforation occurs. The mechanism of failure can be explained by tensile failure, increase and cohesion of planar cracks, formation of voids, and shear instabilities [26]. 
Composites impacted by a high velocity projectile passes through three stages, the first one is just after the projectile hits the target where compression occurs directly below the projectile face, the second one is when the projectile moves on causing a bulge on the rear face of the target, the third and last one is when the projectile totally penetrate the target causing a plug [27].

\section{Method and Materials}

In this section, the details of the methodology used in the paper is presented:

- Firs, the used numerical method is explained briefly;

- Then, the geometry of both the projectile and the proposed target is described as well as the finite element mesh that was chosen to give accurate results;

- The material properties were defined based on previous literature;

- After that, a validation model is analysed and compared to previous experimental results to ensure the accuracy and efficiency of the numerical model;

- Finally, the models are divided into two groups depending on the proposed layer combinations, each group consists of four models, and the detailed geometry and location of reinforcement layer are presented.

\subsection{Numerical Analysis}

With the increasing power and speed numerical FE codes and explicit dynamic solvers, it is possible to use numerical analysis and computer simulation to model any ballistic impact case. The hydro code Autodyne is one of the most efficient codes used to simulate ballistic impact problems and it's used in this paper to model the depth of penetration and the damage in concrete targets. The Lagrangian formulation was chosen to simulate both the projectile and the concrete target.

In Lagrangian formulation, each grid point has different material coordinates and elements are created by connecting the grid points. The element or the mesh deforms with the body, i.e. both the grid nodes and the material points change position as the body deforms but the position of the material points relative to the grid nodes remains fixed as shown in Figure 2. The grid points are forced to move with the element when the body is subjected to deformation.

The main difficulty of Lagrangian mesh is the severe distortion that usually occurs causing stability problems and breaking the discretization. Deformations also cause the mesh to become ill-conditioned and result in decreasing stable time steps and mesh entanglement. This problem can be solved by defining an erosion mechanisms that can remove the distorted elements to allow the calculation to continue. The main advantages of this numerical formulation are the fast solution due to fewer computations per cycle; the high accuracy in describing the material interfaces; the automatic satisfaction of the mass conservation; the ability to apply various boundary conditions; and the availability to handle damage and plasticity.

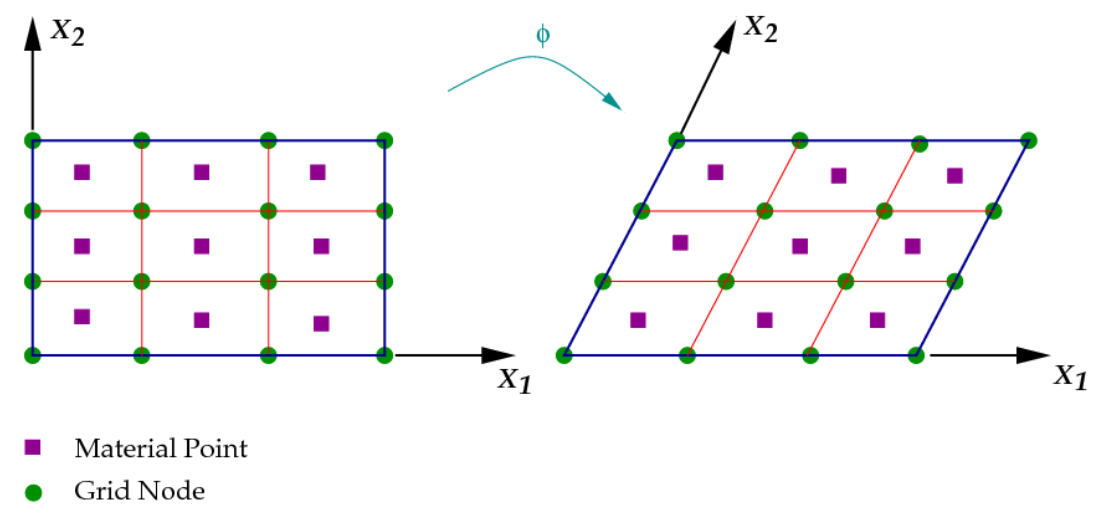

Figure 2. Lagrangian mesh before and after body deformation

\subsection{Geometry and Mesh Description}

The geometry of the simulated concrete block target is $(500 \times 500 \times 400 \mathrm{~mm})$, the reinforcement materials are of thickness $9 \mathrm{~mm}$ located at $50 \mathrm{~mm}$ and $109 \mathrm{~mm}$ from the face of concrete target, the $9 \mathrm{~mm}$ thickness is divided to three layers of $3 \mathrm{~mm}$ each and those layers are filled of different material for each case.

The concrete block is symmetric around $\mathrm{X}$ and $\mathrm{Y}$ axis $(\mathrm{X}=0$ and $\mathrm{Y}=0)$; to take benefit of the symmetry condition and to reduce the computational domain, the block is represented by its quarter $(250 \times 250 \times 400 \mathrm{~mm})$ as shown in 
Figure 3. The concrete region local to the projectile $(100 \times 100 \mathrm{~mm})$ which experience large deformations is defined by a fine mesh of $(2.5 \times 2.5 \times 3 \mathrm{~mm})$ in $i, j$ and $k$ directions and a grade zoning is defined for the region far from the projectile in $i$ and $j$ directions, where little or no deformations are occurred, to reduce the computational time.

The projectile geometry has a diameter of $23 \mathrm{~mm}$ and a length of $64 \mathrm{~mm}$; it is modelled as a 1/4 cylinder, the geometry and mesh description of projectile are shown in Figure 4.

The model boundary condition is fixed from the side and the projectile has a velocity of $960 \mathrm{~m} / \mathrm{s}$ in Z-direction.

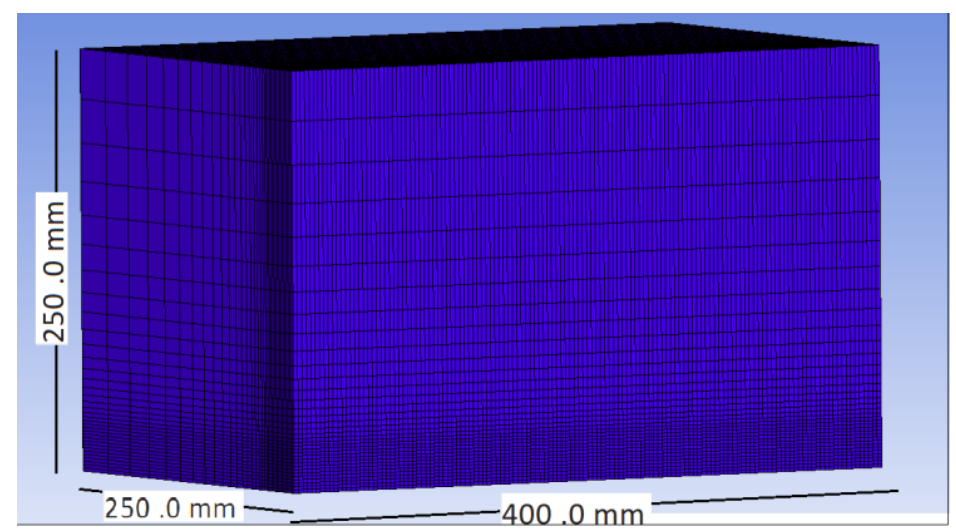

Figure 3. Concrete block geometry and meshing
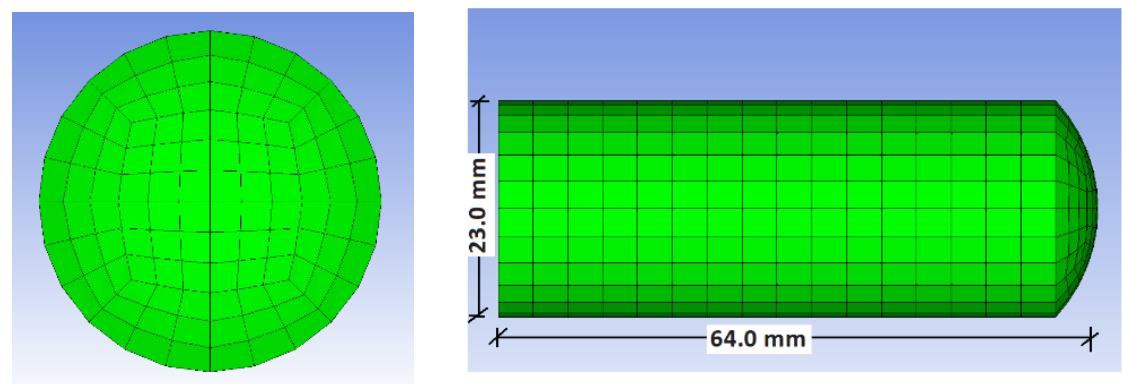

Figure 4. Projectile geometry and meshing.

\subsection{Material Description}

The material models are chosen from AUTODYN library to simulate the used materials as following: STEEL4340 is used to simulate the projectile, while CONC-35MPA is used to simulate the plain concrete of unconfined compressive strength $35 \mathrm{MPA} ; \mathrm{AL}_{2} \mathrm{O}_{3}-99.7 \%$ is chosen to model ceramic material; AL-6061-T6 is chosen to simulate the aluminium alloy; TEFLON for the polymer PTFE (known as Teflon) and KEV-EPOXY for the composite Kevlar epoxy. The details of materials description are shown in Tables 1 to 6 where the Equation of State, the strength model and the failure model for each material are presented as well as the erosion model if existed.

Table 1. Material constants for steel (STEEL4340)

\begin{tabular}{|c|c|c|c|}
\hline Parameter & Value & Parameter & Value \\
\hline Equation of state & Johnson Cook & Hardening Constant (KPa) & $1.79 \mathrm{E}+07$ \\
\hline Reference density (gm/cm3) & 7.83 & Hardening exponent & 0.26 \\
\hline Bulk modulus (KPa) & $1.67 \mathrm{E}+08$ & Strain rate constant & 0.014 \\
\hline Reference temperature $(\mathrm{K})$ & 300 & Thermal softening exponent & 1.03 \\
\hline Specific Heat (C.V.) (j/kg K) & 477 & Melting temperature (k) & 1793 \\
\hline Strength Model & Johnson Cook & Ref. Strain rate $(/ \mathrm{s})$ & 1.00 \\
\hline Shear modulus (KPa) & $7.98 \mathrm{E}+07$ & Erosion model & Geometric strain \\
\hline Yield Stress (KPa) & $1.73 \mathrm{E}+06$ & erosion strain & 3.50 \\
\hline
\end{tabular}


Table 2. Material constants for concrete (CONC-35MPA)

\begin{tabular}{llll}
\hline Parameter & Value & Parameter & Value \\
\hline Equation of state & P-alpha & Failure surface parameter A & 2 \\
Reference density $\left(\mathrm{gm} / \mathrm{cm}^{3}\right)$ & 2.7 & Failure surface exponent $\mathrm{N}$ & 0.7 \\
Porous density $\left(\mathrm{gm} / \mathrm{cm}^{3}\right)$ & 2.350 & Tens./comp. meridian ratio & 0.6805 \\
Porous sound speed $(\mathrm{m} / \mathrm{s})$ & $2.92 \mathrm{E}+03$ & Brittle to ductile Transit & 0.0105 \\
Initial compaction pressure $(\mathrm{KPa})$ & $2.33 \mathrm{E}+04$ & G (elas. $) / \mathrm{G}$ (elas.-plas.) & 2 \\
Solid compaction pressure $(\mathrm{KPa})$ & $6.00 \mathrm{E}+06$ & compaction curve & Standard \\
Compaction exponent $\mathrm{n}$ & 3.00 & Elastic strength/ft & 0.7 \\
Solid EOS & Polynomial & Elastic strength/fc & 0.53 \\
Bulk modulus A1 $(\mathrm{KPa})$ & $3.53 \mathrm{E}+07$ & Use cap on elastic surface & 1 \\
Parameter A2 $(\mathrm{KPa})$ & $3.96 \mathrm{E}+07$ & Fractured strength constant & 1.50 \\
Parameter A3 $(\mathrm{KPa})$ & $9.04 \mathrm{E}+06$ & Fractured strength exponent & 0.61 \\
Parameter B0 & 1.22 & Compressive strain rate & 0.032 \\
Parameter B1 & 1.22 & Tensile strain rate exponent & 0.025 \\
Parameter T1 $(\mathrm{KPa})$ & $3.53 \mathrm{E}+07$ & Max. fracture strength ratio & $1.00 \mathrm{E}+20$ \\
Parameter T2 $(\mathrm{KPa})$ & 0.00 & Failure Model & RHT Concrete \\
Reference temperature $(\mathrm{K})$ & 300.00 & Damage constant D1 & 0.04 \\
Specific Heat $(\mathrm{C} . \mathrm{V}).(\mathrm{j} / \mathrm{kg} \mathrm{K})$ & 654.00 & Damage exponent D2 & 1.00 \\
Strength Model & RHT Concrete & Min. strain to failure & 0.01 \\
Shear modulus $(\mathrm{KPa})$ & $1.67 \mathrm{E}+07$ & Residual shear modulus frac. & 0.13 \\
Compressive strength fc $(\mathrm{KPa})$ & $3.50 \mathrm{E}+04$ & Tensile failure model & Hydro tens. \\
Tensile strength ft/fc & 0.088 & Erosion model & Geometric strain \\
shear strength fs/fc & 0.18 & erosion strain & 1.045 \\
\hline & & & \\
\hline
\end{tabular}

Table 3. Material constants for ceramic material (AL2O3-99.7\%)

\begin{tabular}{llll}
\hline Parameter & Value & Parameter & Value \\
\hline Equation of state & Polynomial & Intanct Strength Constant & $9.89 \mathrm{E}-01$ \\
Reference density $(\mathrm{gm} / \mathrm{cm} 3)$ & 3.80 & Intanct Strength Exponent & 1.00 \\
Bulk modulus A1 $(\mathrm{KPa})$ & $2.00 \mathrm{E}+08$ & Max. Fracture Strength Ratio & 0.50 \\
Parameter A2 $(\mathrm{KPa})$ & 0.00 & $\underline{\text { Failure Model }}$ & Johnson-Holmquist \\
Parameter T1 $(\mathrm{KPa})$ & $2.00 \mathrm{E}+08$ & Damage Constant D1 & $-2.90 \mathrm{E}+04$ \\
Parameter T2 $(\mathrm{KPa})$ & 0.00 & Damage Constant D2 & 0.01 \\
Strength Model & Johnson-Holmquist & Bulking constant, Beta & 1.00 \\
Shear modulus $(\mathrm{MPa})$ & $1.35 \mathrm{E}+08$ & Erosion model & none \\
Hugoniot Elastic Limit $(\mathrm{KPa})$ & $5.90 \mathrm{E}+06$ & & \\
\hline
\end{tabular}

Table 4. Material constants for aluminium alloy (Al-6066 T6)

\begin{tabular}{llll}
\hline Parameter & Value & Parameter & Value \\
\hline Equation of state & Shock & Yield Stress (KPa) & $2.90 \mathrm{E}+05$ \\
Reference density (gm/cm3) & 2.703 & Maximum Yield Stress $(\mathrm{KPa})$ & $6.80 \mathrm{E}+05$ \\
Gruneisen coefficient & 1.97 & Hardening Constant & 125 \\
Parameter C1 (m/s) & 1.97 & Hardening exponent & 0.10 \\
Parameter S1 & 1.40 & Derivative dG/dP & 1.80 \\
Reference temperature $(\mathrm{K})$ & 300 & Derivative dG/dT & $-1.70 \mathrm{E}+04$ \\
Specific Heat $(\mathrm{j} / \mathrm{kg} \mathrm{K})$ & 885 & Derivative dY/dP & 0.0189 \\
Strength Model & Steinberg Guinan & Melting temperature & $1.22 \mathrm{E}+03$ \\
Shear modulus $(\mathrm{KPa})$ & $2.76 \mathrm{E}+07$ & Failure Model & none \\
\hline
\end{tabular}


Table 5. Material constants for Teflon (TEFLON)

\begin{tabular}{llll}
\hline Parameter & Value & Parameter & Value \\
\hline Equation of state & Shock & $\underline{\text { Strength Model }}$ & von Mises \\
Reference density $(\mathrm{gm} / \mathrm{cm} 3)$ & 2.16 & Shear modulus $(\mathrm{KPa})$ & $2.33 \mathrm{E}+06$ \\
Gruneisen coefficient & 0.9 & Yield Stress $(\mathrm{KPa})$ & $5.00 \mathrm{E}+04$ \\
Parameter C1 $(\mathrm{m} / \mathrm{s})$ & $1.34 \mathrm{E}+03$ & Failure Model & Hydro (Pmin) \\
Parameter S1 & 1.93 & Hydro tensile limit & $-1.00 \mathrm{E}+06$ \\
Reference temperature $(\mathrm{K})$ & 0 & Reheal & yes \\
Specific Heat $(\mathrm{j} / \mathrm{kg} \mathrm{K})$ & 0 & Crack softening & no \\
\hline
\end{tabular}

Table 6. Material constants for Kevlar epoxy (KEV-EPOXY)

\begin{tabular}{|c|c|c|c|}
\hline Parameter & Value & Parameter & Value \\
\hline Equation of state & Ortho & $\underline{\text { Failure Model }}$ & Material stress/strain \\
\hline Reference density $\left(\mathrm{gm} / \mathrm{cm}^{3}\right)$ & 1.65 & Tensile failure stress $11(\mathrm{KPa})$ & 100.00 \\
\hline stiffness & stiffness matrix & Tensile failure stress $22(\mathrm{KPa})$ & 100.00 \\
\hline $\mathrm{C} 11(\mathrm{KPa})$ & $3.45 \mathrm{E}+06$ & Tensile failure stress $33(\mathrm{KPa})$ & 100.00 \\
\hline $\mathrm{C} 22(\mathrm{KPa})$ & $1.35 \mathrm{E}+07$ & Maximum shear stress $12(\mathrm{KPa})$ & 100.00 \\
\hline $\mathrm{C} 33(\mathrm{KPa})$ & $1.35 \mathrm{E}+07$ & Maximum shear stress $23(\mathrm{KPa})$ & 101.00 \\
\hline $\mathrm{C} 12(\mathrm{KPa})$ & $1.14 \mathrm{E}+06$ & Maximum shear stress $31(\mathrm{KPa})$ & 101.00 \\
\hline $\mathrm{C} 23(\mathrm{KPa})$ & $1.20 \mathrm{E}+06$ & Tensile failure strain 11 & 0.01 \\
\hline $\mathrm{C} 31(\mathrm{KPa})$ & $1.14 \mathrm{E}+06$ & Tensile failure strain 22 & 0.08 \\
\hline Shear modulus $12(\mathrm{KPa})$ & $1.00 \mathrm{E}+06$ & Tensile failure strain 33 & 0.08 \\
\hline Shear modulus $23(\mathrm{KPa})$ & $1.00 \mathrm{E}+06$ & Maximum shear strain 12 & 100.00 \\
\hline Shear modulus $31(\mathrm{KPa})$ & $1.00 \mathrm{E}+06$ & Maximum shear strain 23 & 101.00 \\
\hline Bulk Shear A1 (KPa) & $4.15 \mathrm{E}+06$ & Maximum shear strain 31 & 101.00 \\
\hline Parameter A2 (KPa) & $4.00 \mathrm{E}+07$ & Residual shear stiffness & 0.20 \\
\hline Parameter T1 (KPa) & $4.15 \mathrm{E}+06$ & Maximum residual shear (KPa) & 100.00 \\
\hline Parameter T2 (KPa) & 0.00 & Decomposition Temperature (K) & 700.00 \\
\hline$\underline{\text { Strength model }}$ & Elastic & Matrix melt temperature (K) & 101.00 \\
\hline Shear modulus (KPa) & $1.00 \mathrm{E}+06$ & $\underline{\text { Erosion model }}$ & none \\
\hline
\end{tabular}

\subsection{Validation Model}

An experimental study was conducted by Mohamed et al. [28] on a concrete block with the same dimensions (500 $\times 500 \times 400 \mathrm{~mm}$ ) having a compressive strength of $35 \mathrm{MPa}$ and a density of $2.350 \mathrm{gm} / \mathrm{cm}^{3}$, the block was subjected to a similar projectile of diameter $23 \mathrm{~mm}$ and having a striking velocity about $970 \mathrm{~m} / \mathrm{sec}$ as shown in Figure 5 . The concrete target we supported by the steel frame along its perimeter to prevent movement in both directions, then it was fired by the projectile. Figure 6 shows the concrete block before and after impact, the recorded depth of penetration was $400 \mathrm{~mm}$ and the front and rear faces were fully damaged.
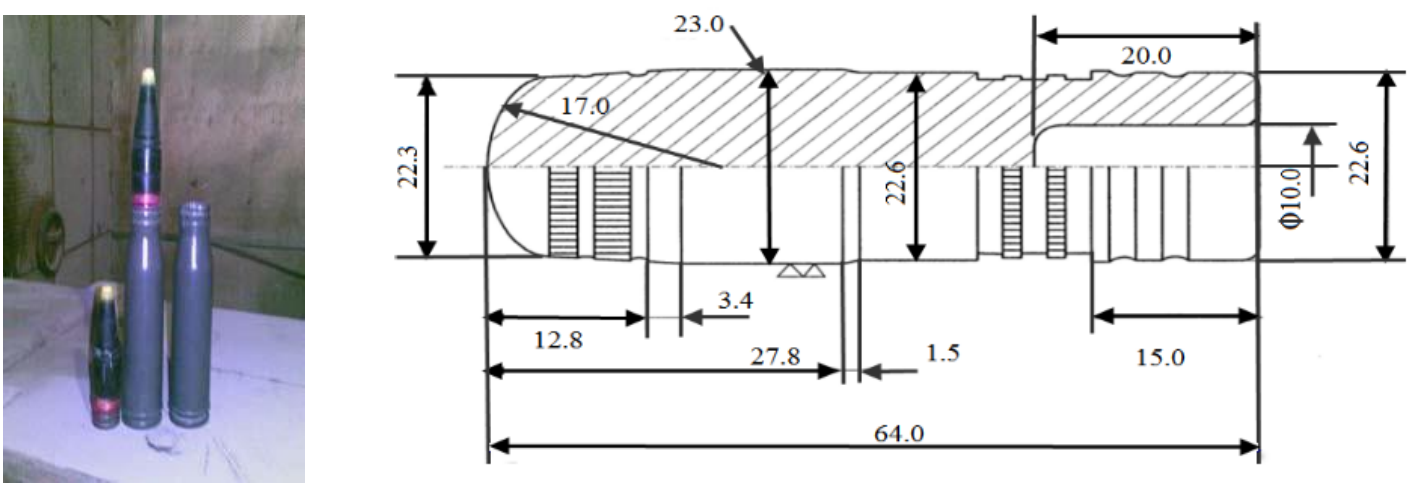

Figure 5. Dimensions of the projectile [29] 

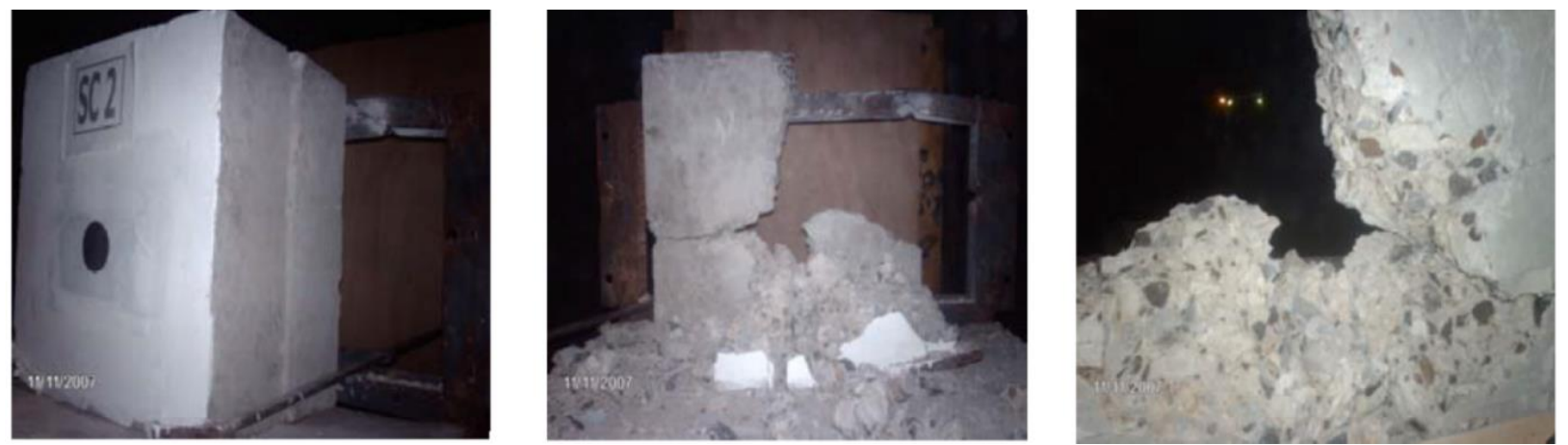

Figure 6. The concrete target before and after impact [29]

The first model in this paper is used for numerical validation. The model that was simulated using the same dimensions and properties of the experimental model, recorded a depth of penetration of $390 \mathrm{~mm}$ when it was subjected to a $23 \mathrm{~mm}$ projectile with a velocity of $960 \mathrm{~m} / \mathrm{sec}$ as shown in Figure 7; which shows a good agreement with the experiment result of the plain concrete block subjected to the same projectile. Figure 8 show the results the damage contour of concrete target, it is obvious that the block was fully damaged.

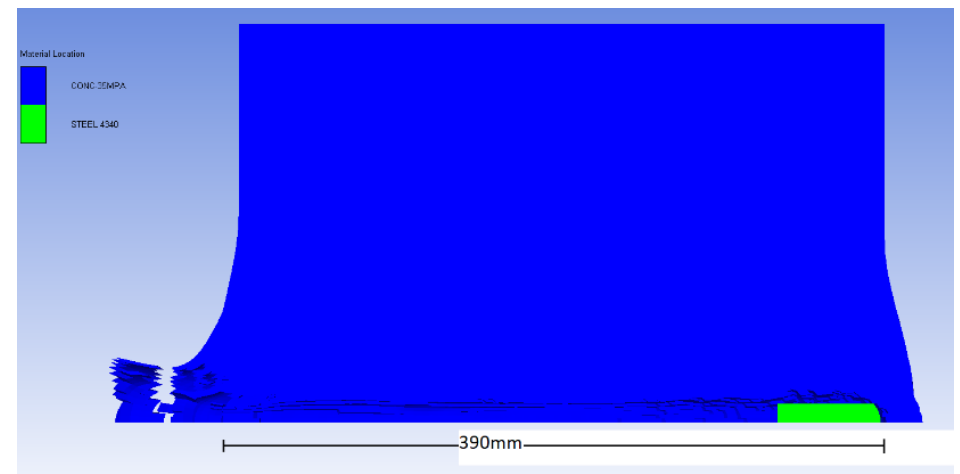

Figure 7. Depth of penetration for concrete with no reinforcement
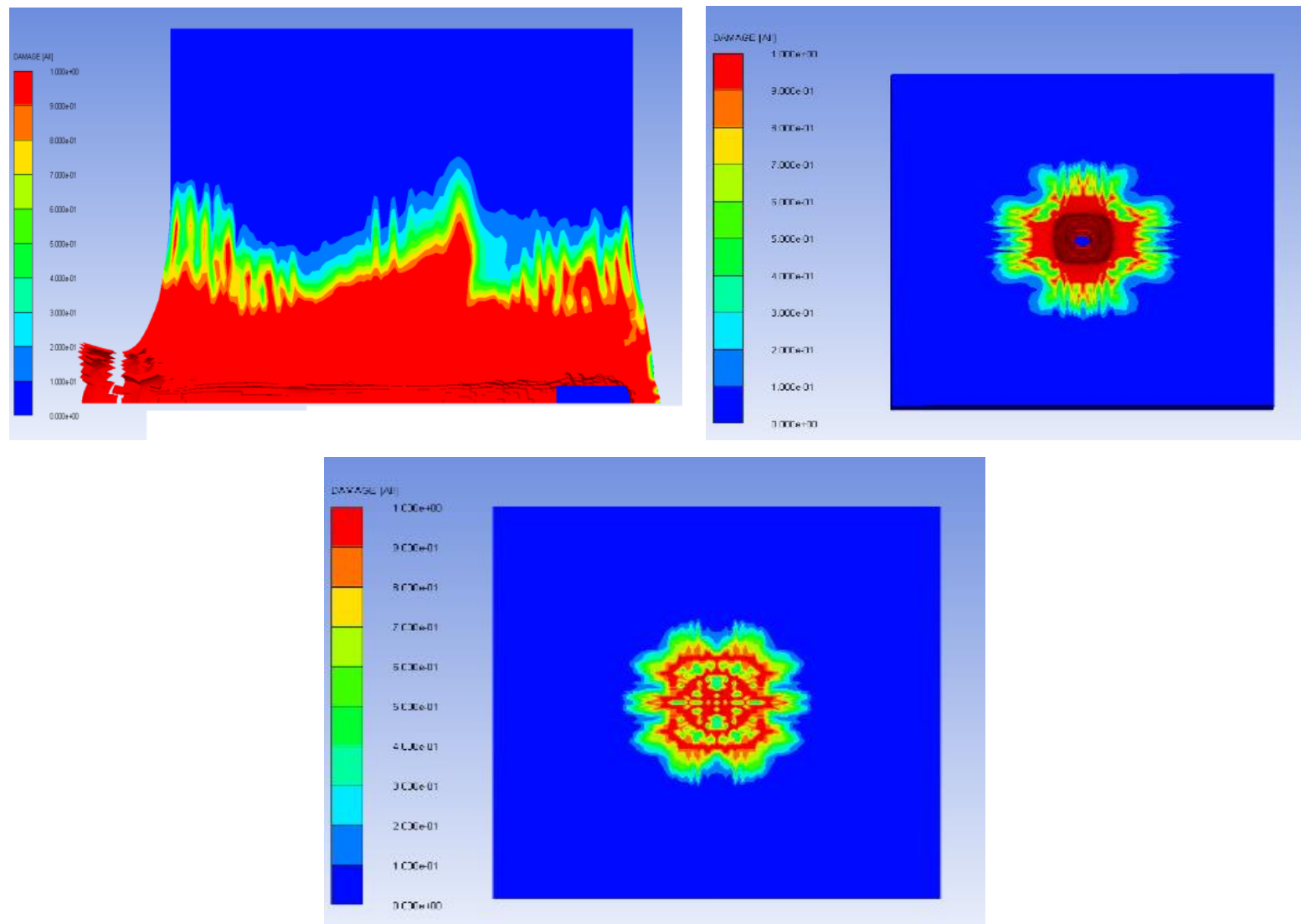

Figure 8. The damage contour for concrete target with no reinforcement: side section, front face and rear face 


\subsection{Numerical Models}

The models simulated in this paper are reinforced by the chosen material combinations with a thickness of $9 \mathrm{~mm}$ and at a distance of 50 and $109 \mathrm{~mm}$ from the face of the concrete target. The models are divided into 2 groups based on the material combination geometry: the first group (Group 1) is reinforced by a combination of two layers, the first layer is $6 \mathrm{~mm}$ (Ceramic or AL.) and the second layer is $3 \mathrm{~mm}$ (KE or Teflon) as shown in Figure 9, while the second group (Group 2) is reinforced by a combination of 3 layers of $3 \mathrm{~mm}$ each, the first and third layers are ceramic or aluminium and the second one is KE or Teflon as shown in Figure 10. The two groups are presented in detail in Table 7.
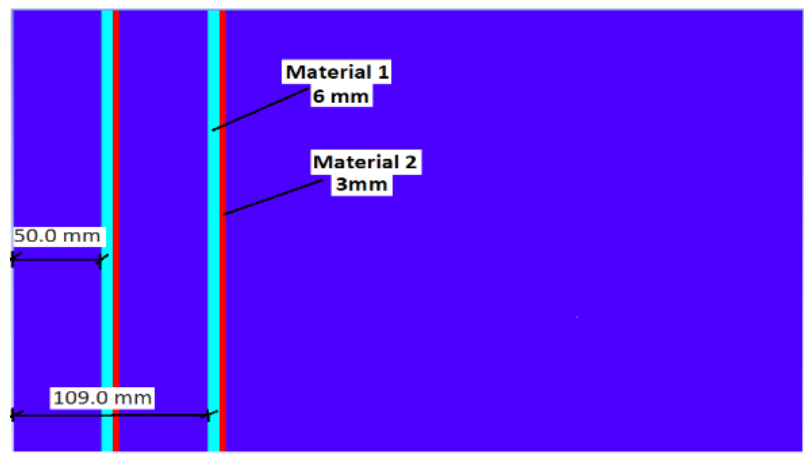

Figure 9. Group 1 combination and geometry

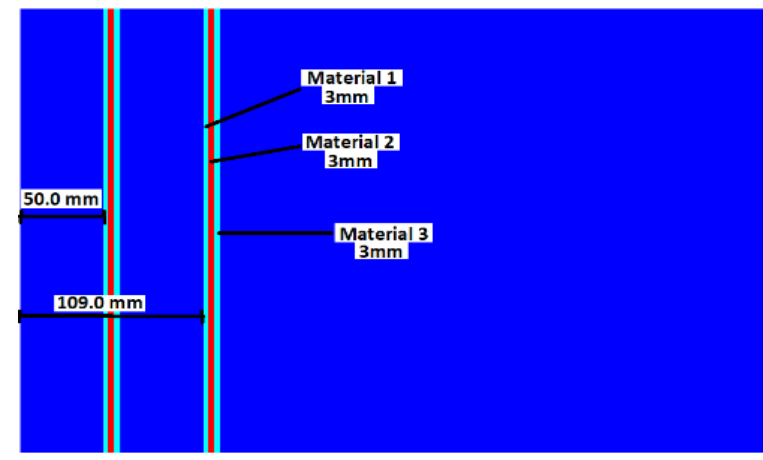

Figure 10. Group 2 combination and geometry

Table 7. Materials and thickness of layer combinations for Groups 1 and 2

\begin{tabular}{|c|c|c|c|c|c|c|c|}
\hline \multirow{7}{*}{ 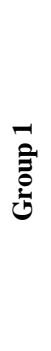 } & & \multicolumn{3}{|c|}{ 1st layer at $50 \mathrm{~mm}(\mathrm{t}=9 \mathrm{~mm})$} & \multicolumn{3}{|c|}{ 2nd layer at $109 \mathrm{~mm}(\mathrm{t}=9 \mathrm{~mm})$} \\
\hline & تृ & \multicolumn{2}{|c|}{ Material 1} & Material 2 & \multicolumn{2}{|c|}{ Material 1} & Material 2 \\
\hline & $z$ & \multicolumn{2}{|c|}{$6 \mathrm{~mm}$} & $3 \mathrm{~mm}$ & \multicolumn{2}{|c|}{$6 \mathrm{~mm}$} & $3 \mathrm{~mm}$ \\
\hline & M1A & \multicolumn{2}{|c|}{ Ceramic } & Kevlar Epoxy & \multicolumn{2}{|c|}{ Ceramic } & Kevlar Epoxy \\
\hline & M1B & \multicolumn{2}{|c|}{ Ceramic } & Teflon & \multicolumn{2}{|c|}{ Ceramic } & Teflon \\
\hline & $\mathrm{M} 1 \mathrm{C}$ & \multicolumn{2}{|c|}{ Aluminium } & Kevlar Epoxy & \multicolumn{2}{|c|}{ Aluminium } & Kevlar Epoxy \\
\hline & M1D & \multicolumn{2}{|c|}{ Aluminium } & Teflon & \multicolumn{2}{|c|}{ Aluminium } & Teflon \\
\hline \multirow{7}{*}{ ڤ̊ } & \# & \multicolumn{3}{|c|}{ 1st layer at $50 \mathrm{~mm}(\mathrm{t}=9 \mathrm{~mm})$} & \multicolumn{3}{|c|}{ 2nd layer at $109 \mathrm{~mm}(\mathrm{t}=9 \mathrm{~mm})$} \\
\hline & تِ & Material 1 & Material 2 & Material 3 & Material 1 & Material 2 & Material 3 \\
\hline & $<$ & $3 \mathrm{~mm}$ & $3 \mathrm{~mm}$ & $3 \mathrm{~mm}$ & $3 \mathrm{~mm}$ & $3 \mathrm{~mm}$ & $3 \mathrm{~mm}$ \\
\hline & M2A & Ceramic & Kevlar Epoxy & Ceramic & Ceramic & Kevlar Epoxy & Ceramic \\
\hline & M2B & Ceramic & Teflon & Ceramic & Ceramic & Teflon & Ceramic \\
\hline & M2C & Aluminium & Kevlar Epoxy & Aluminium & Aluminium & Kevlar Epoxy & Aluminium \\
\hline & M2B & Aluminium & Teflon & Aluminium & Aluminium & Teflon & Aluminium \\
\hline
\end{tabular}

\section{Results and Discussion}

\subsection{Projectile Kinetic Energy}

The rate of dissipation of projectile kinetic energy (KE) is the most important factor to determine its depth of penetration into the target.

This section presents a comparison between the dissipation of projectile KE in the model of plain concrete target and the four models of Group1 where the target is reinforced by two layers of different combinations as mentioned before in Table 7.

It's obvious from the presented graphs that the rate of the projectile KE dissipation with time for Group1 models is too much higher than the model of plain concrete: Figure 11 presents the case of plain concrete and shows that the projectile $\mathrm{KE}$ is totally lost after $1.6 \mathrm{~ms}$ approximately, while in the other models, the time varies from $0.28 \mathrm{~ms}$ to 0.36 $\mathrm{ms}$ as shown in Figures 12.1 to 12.4. This result demonstrates the efficiency of using such materials in decreasing the rate of KE dissipation of projectile and, as a consequence, decrease its depth of penetration into the target. 


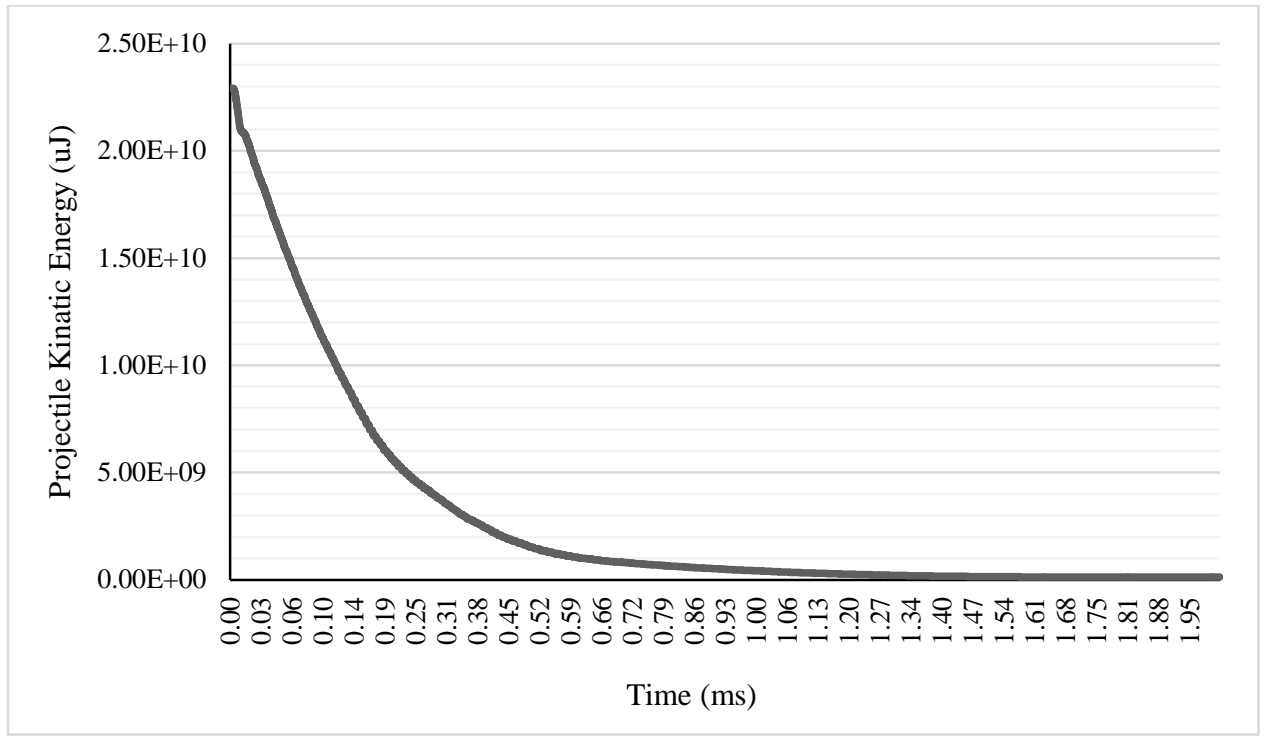

Figure 11. Projectile KE decrease with time for plain concrete model

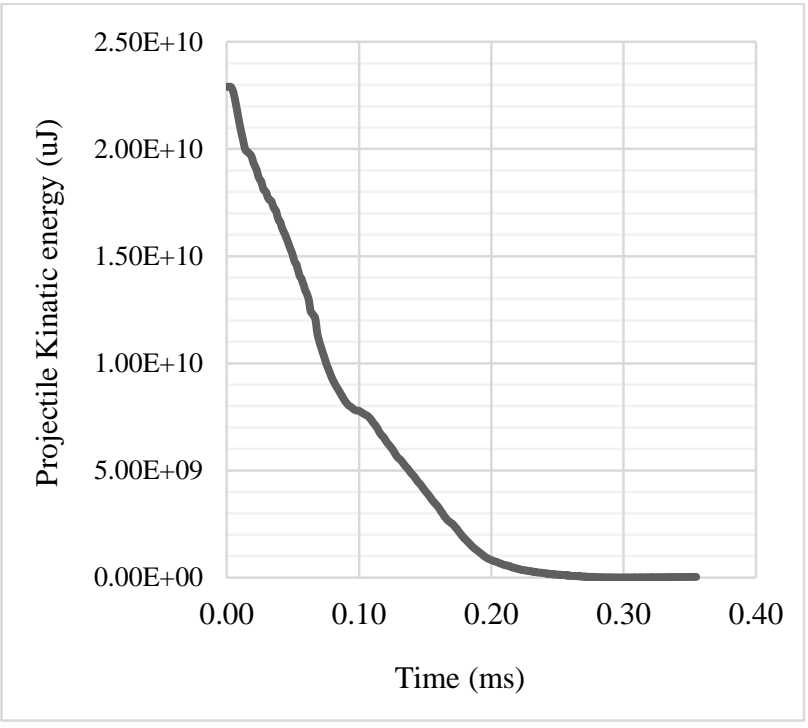

Figure 12. 1: Projectile KE decrease for model M1A (ceramic/KE)

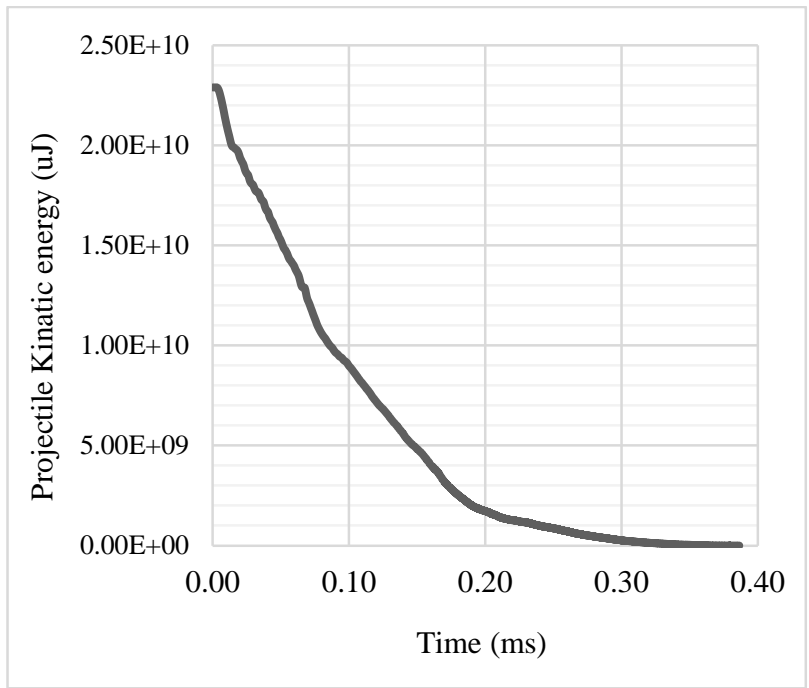

Figure 12. 3: Projectile KE decrease for model M1C (Aluminum/KE)

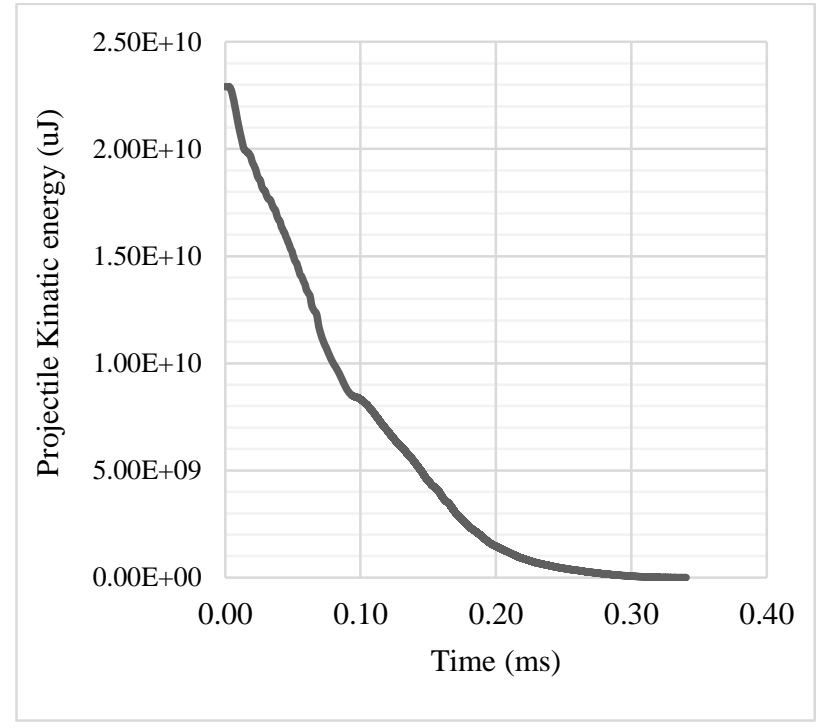

Figure 12. 2: Projectile KE decrease for model M1B (ceramic/ Teflon)

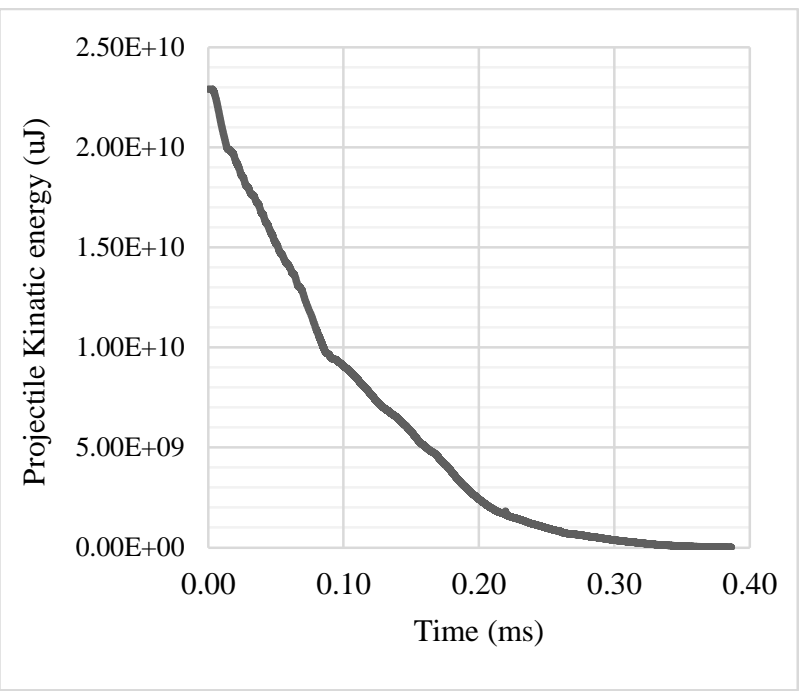

Figure 12. 4: Projectile KE decrease for model M1D (Aluminum/ Teflon) 


\subsection{Projectile Depth of Penetration}

The projectile depth of penetration (DP) the concrete target with different reinforcements and was captured and represented in this section: the results of the two groups show a good enhancement in the concrete target resistance: the DP is reduced by about $69.6 \%$ for model M1A (ceramic/KE) where the recorded DP is $118.6 \mathrm{~mm}$ (Figure 13.1) which is the lowest recorded DP within the eight models. The second low DP is obtained from model M2C (Aluminum/KE/Aluminum) and it equals to $123.2 \mathrm{~mm}$ which represents a DP reduction of $68.4 \%$ compared to the plain concrete model (Figure 13.7). Model M1B (ceramic/Teflon) records the third low value for DP which is $129.7 \mathrm{~mm}$ and it represents a reduction of $66.7 \%$. The forth low DP occurred in model M2A (ceramic/KE/ceramic) which is $130.9 \mathrm{~mm}$ with 66.4\% DP reduction. Models M1D, M2B and M1C recorded very close values of 137.3, 137.8 and $139.8 \mathrm{~mm}$ for the DP respectively (Figures 13.4, 13.6 and 13.3). Finally, the maximum DP occurred in model M2D (Aluminum/Teflon/Aluminum) with a value of $143.4 \mathrm{~mm}$ which represents a decrease of $63.2 \%$. The previous results are presented in Table 8 .

Table 8. Projectile depth of penetration values and percentage of reduction

\begin{tabular}{ccccc}
\hline Group & model & Depth of penetration & Reduction of DP \% & Time at velocity $\approx \mathbf{0}$ \\
\hline \multirow{3}{*}{ Group 1 } & M1A & $118.6 \mathrm{~mm}$ & $69.6 \%$ & $0.302 \mathrm{~ms}$ \\
& M1B & $129.7 \mathrm{~mm}$ & $66.7 \%$ & $0.343 \mathrm{~ms}$ \\
& M1C & $139.8 \mathrm{~mm}$ & $64.1 \%$ & $0.386 \mathrm{~ms}$ \\
& M1D & $137.3 \mathrm{~mm}$ & $64.8 \%$ & $0.396 \mathrm{~ms}$ \\
\hline \multirow{5}{*}{ Group 2 } & M2A & $130.9 \mathrm{~mm}$ & $66.4 \%$ & $0.369 \mathrm{~ms}$ \\
& M2B & $137.8 \mathrm{~mm}$ & $64.7 \%$ & $0.381 \mathrm{~ms}$ \\
& M2C & $123.2 \mathrm{~mm}$ & $68.4 \%$ & $0.362 \mathrm{~ms}$ \\
& M2D & $143.4 \mathrm{~mm}$ & $63.2 \%$ & $0.378 \mathrm{~ms}$ \\
\hline
\end{tabular}

\subsection{Concrete Target Damage}

The damage behavior of concrete target is also investigated in this section. A remarkable decrease in the depth of full damage is registered for the eight models with different layers combination compared to the model with no reinforcement. Figure 8 shows that the front and rear faces of concrete with no reinforcement are fully damaged while for the other models, only the front face is fully damaged and the rear face is approximately safe with maximum local damage of $10 \%$ as shown in Figures 14.1 to 14.8 , as the maximum depth of full damage occurred in model M1C (Aluminum/KE) with a value of $179.5 \mathrm{~mm}$, while in case of no reinforcement, the depth of full damage was equal to $400 \mathrm{~mm}$,i.e. the full target depth; which means that the damage of target is decreased of at least 55\%. This remarkable reduction can be explained by the great ability of the used reinforcement materials in absorbing the projectile energy and as a result decrease the concrete target damage.

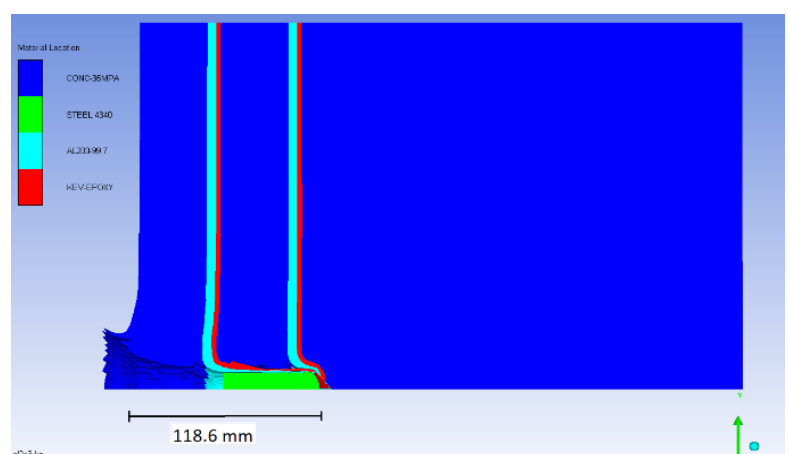

Figure 13. 1: M1A (Ceramic/KE) DP=118.6 mm

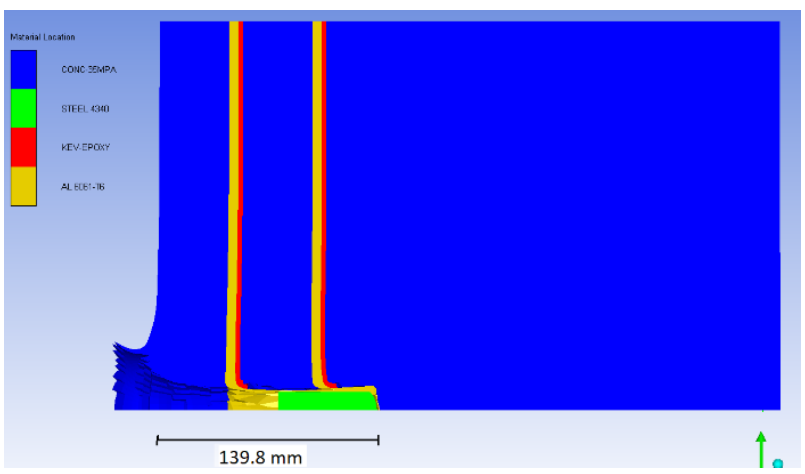

Figure 13. 3: M1C (Aluminum/KE) $D P=139.8 \mathrm{~mm}$

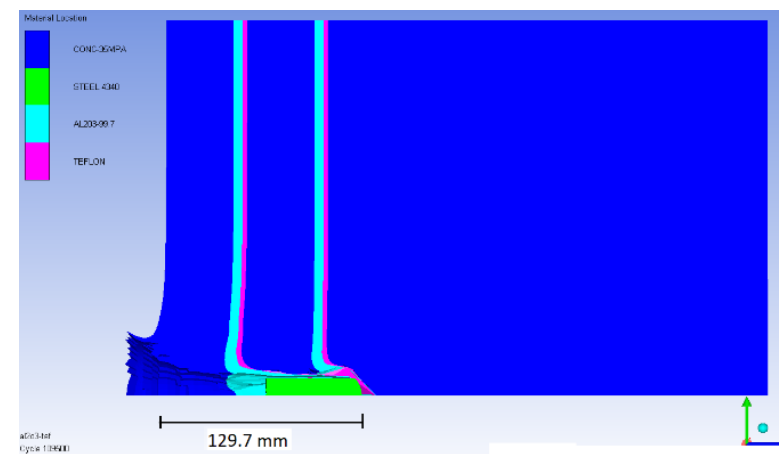

Figure 13. 2: M1B (Ceramic/Teflon) DP=129.7 mm

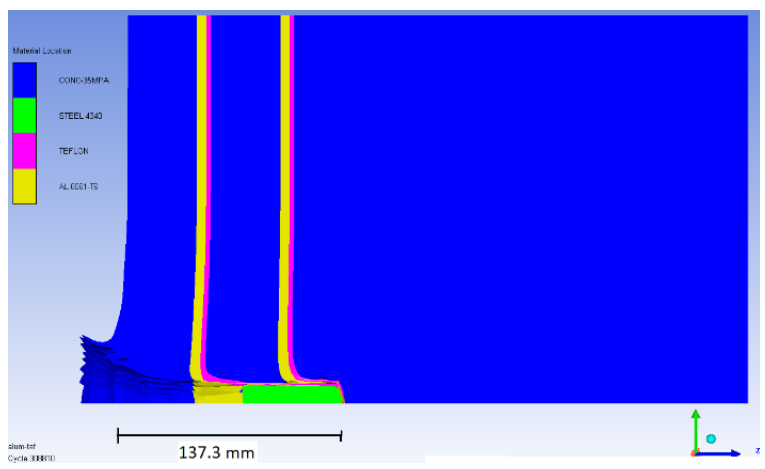

Figure 13. 4: M1D (Aluminum/Teflon) $D P=137.3 \mathrm{~mm}$ 


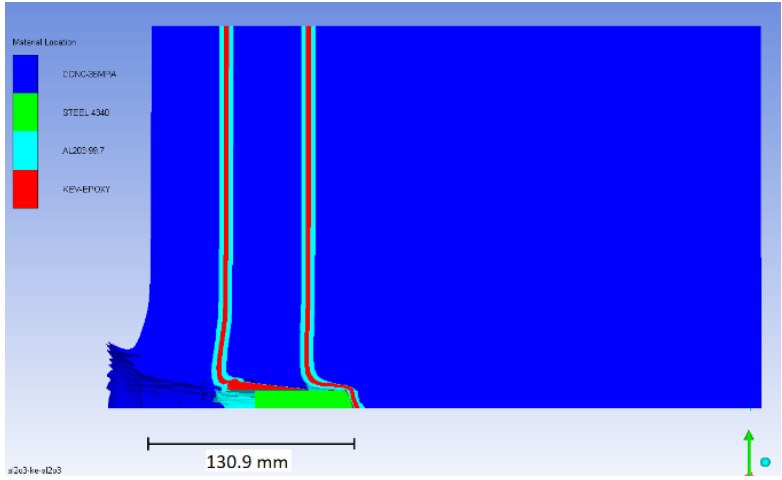

Figure 13. 5: M2A (Ceramic/KE/Ceramic DP=130.9 mm

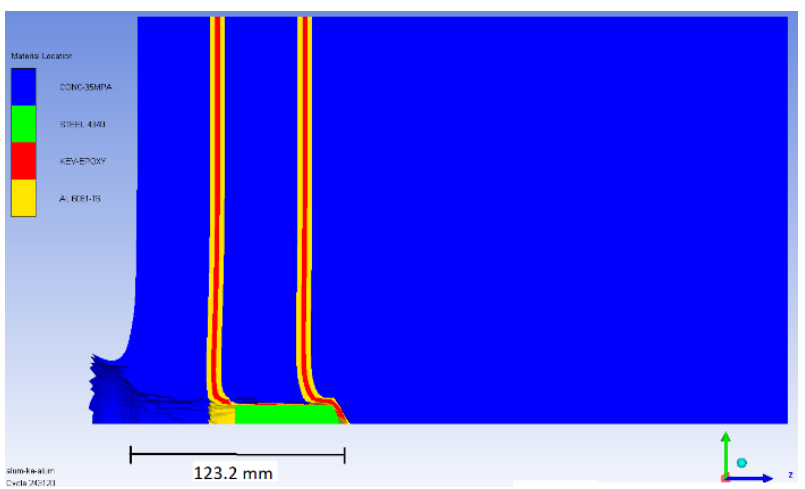

Figure 13. 7: M2C (Aluminum/KE/Aluminum) $\mathrm{DP}=123.2 \mathrm{~mm}$

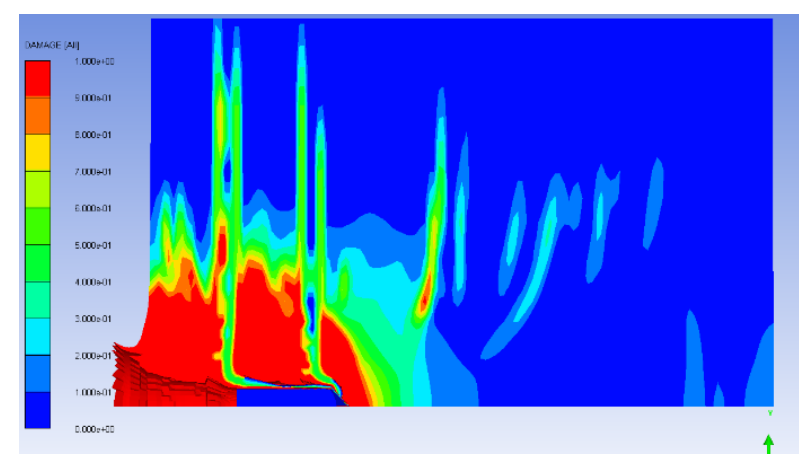

Figure 14. 1: M1A (Ceramic/KE) Full Damage $=142.4 \mathrm{~mm}$

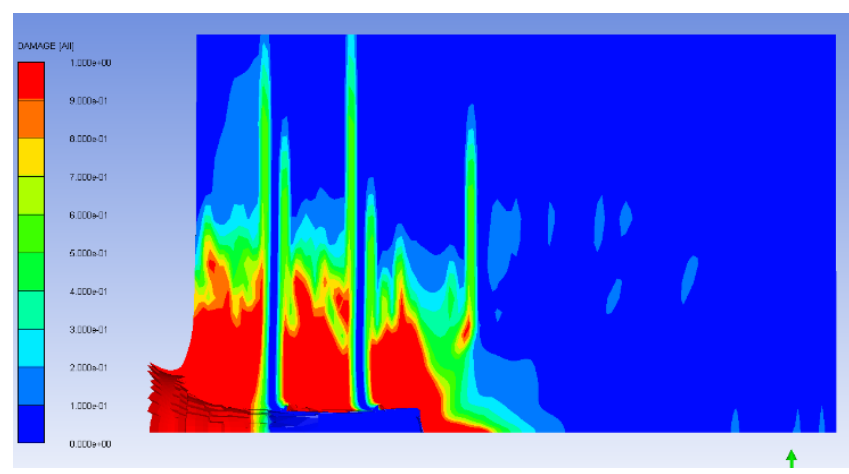

Figure 14. 3: M1C (Aluminum/KE) Full Damage $=179.5 \mathrm{~mm}$

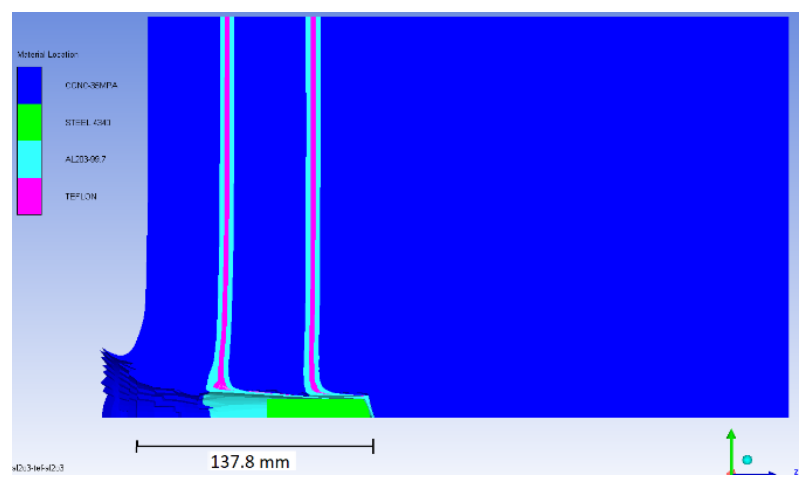

Figure 13. 6: M2B (Ceramic/Teflon/Ceramic) $D P=137.8 \mathrm{~mm}$

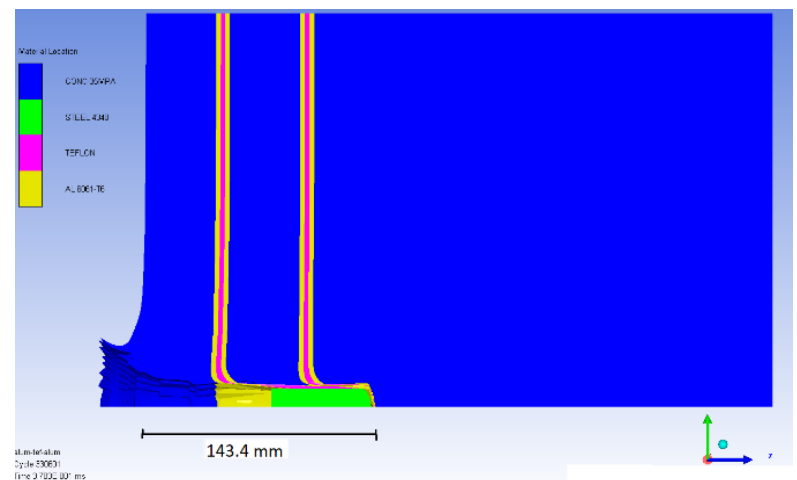

Figure 13. 8: M2D (Aluminum/Teflon/Aluminum) $\mathrm{DP}=143.4 \mathrm{~mm}$

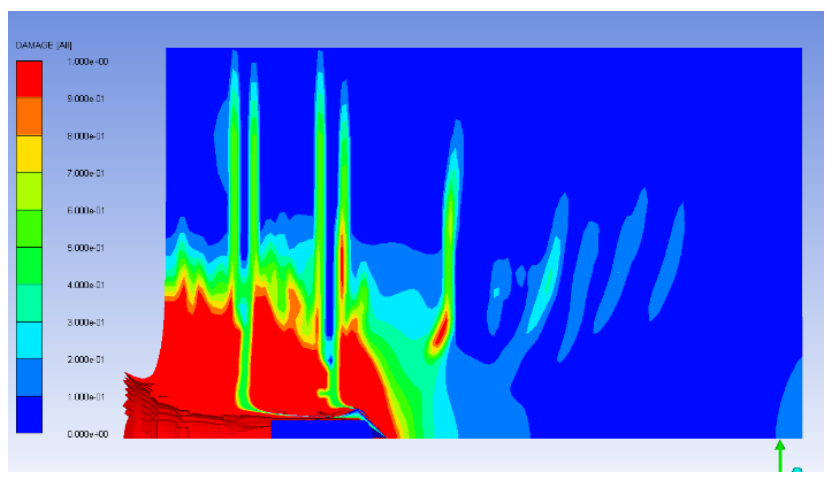

Figure 14. 2: M1B (Ceramic/Teflon) Full Damage $=147.8 \mathrm{~mm}$

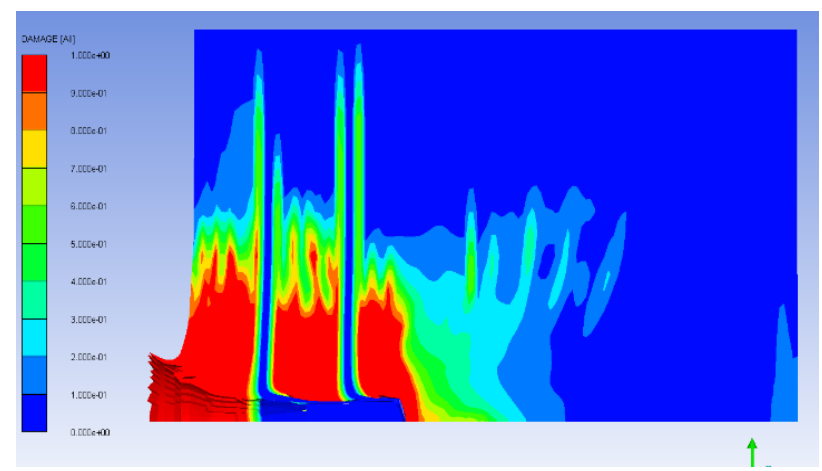

Figure 14. 4: M1D (Aluminum/Teflon) Full Damage $=150.8 \mathrm{~mm}$ 


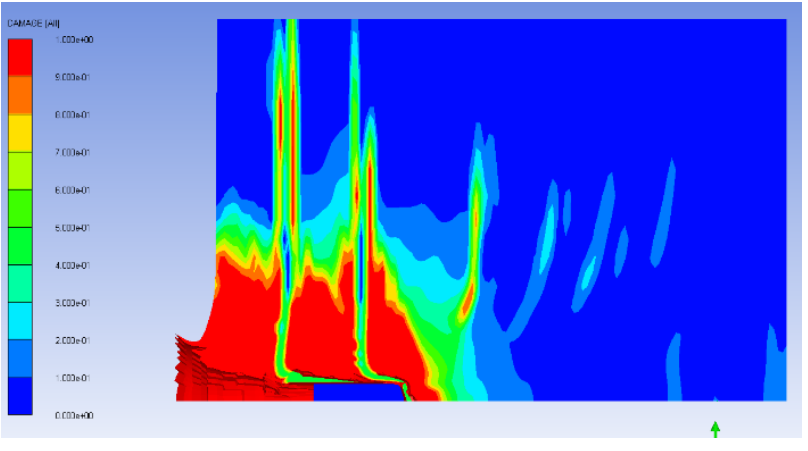

Figure 14. 5: M2A (Ceramic/KE/Ceramic) Full Damage $=156.0 \mathrm{~mm}$

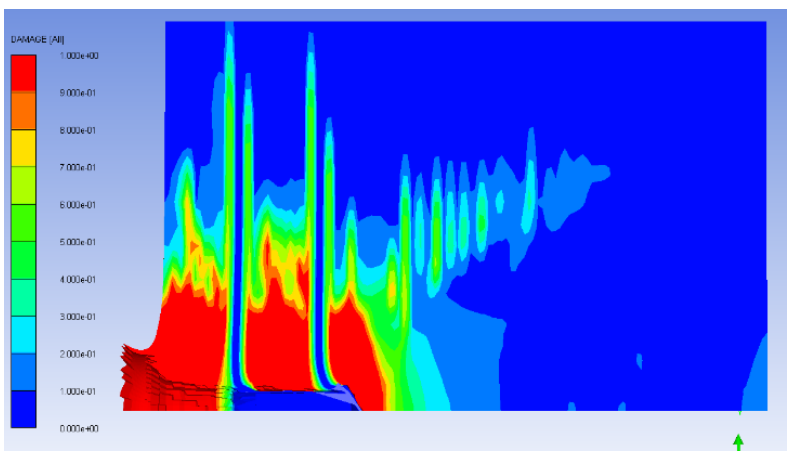

Figure 14. 7: M2C (Aluminum/KE/Aluminum) Full Damage $=145.1 \mathrm{~mm}$

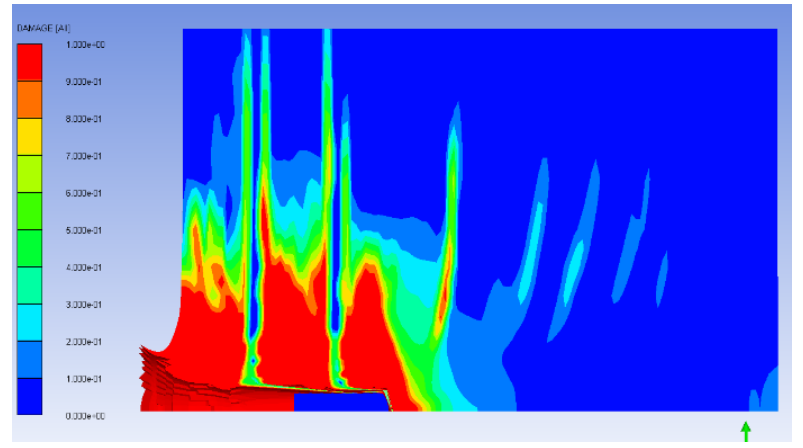

Figure 14. 6: M2B (Ceramic//Teflon/Ceramic) Full Damage $=156.4 \mathrm{~mm}$

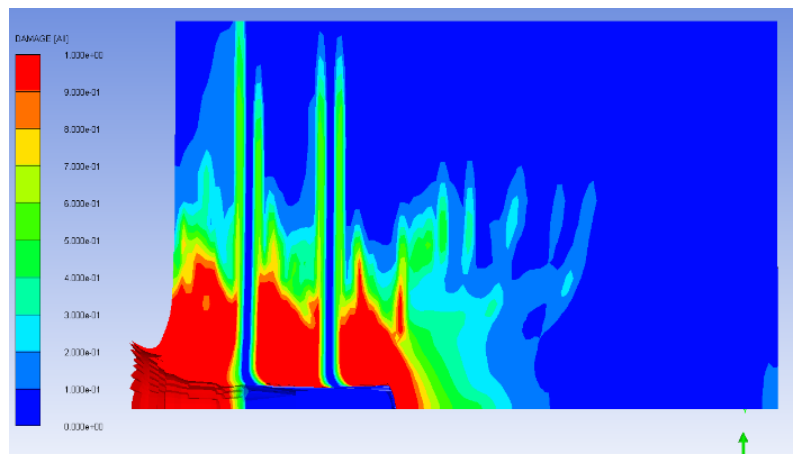

Figure 14. 8: M2D (Aluminum/Teflon/Aluminum) Full Damage $=159.8 \mathrm{~mm}$

\section{Conclusion}

In this paper presents an investigation of the ballistic performance of concrete blocks ) reinforced by different layers of high toughness and energy absorption materials and subjected to high-velocity rigid projectile ( $960 \mathrm{mls})$ and the effect of these layer combinations on the penetration depth of projectile and the resulted damage of concrete . Finite element models were numerally simulated using the Hydrocode Autodyn 3D, and some results were compared to previous experimental work found in literature.

Eight different layer combinations were used as reinforcement for concrete to enhance its resistance to ballistic impact, the effect of these reinforcement on the projectile kinetic energy dissipation was presented, the rate of dissipation of KE was too much higher when using the suggested material reinforcement compared to plain concrete. The projectile depth of penetration into the target was also investigated and the results were presented and the models with new reinforcement showed a very good enhancement in penetration resistance of concrete as the depth of penetration of the projectile was reduced up to $69 \%$. The degree of damage of concrete target due to the impact loading of the projectile was presented as well, the investigated models showed a great reduction in the depth of the damaged part of concrete target as the depth was reduced up to $142.4 \mathrm{~mm}$ instead of $400 \mathrm{~mm}$ for concrete without reinforcement, which means that an improvement of $64.4 \%$ was reached.

Hence from the findings of this work we can say that the concrete reinforced by ceramics or aluminum alloy along with fiber composites or polymers can be used for several applications as it represents a successful anti-penetration composite structure.

\section{Conflict of Interest}

The authors declare no conflict of interest.

\section{References}

[1] NDRC. Effects of impact and explosion. Summary technical report of division 2, Vol 1. Natl Def Res Committee, Washington, DC 1945.

[2] ACE. Fundamentals of protective structures. Report AT1207821. Army Corps Eng 1946.

[3] Forrestal, M.J., B.S. Altman, J.D. Cargile, and S.J. Hanchak. “An Empirical Equation for Penetration Depth of Ogive-Nose Projectiles into Concrete Targets." International Journal of Impact Engineering 15, no. 4 (August 1994): 395-405. doi:10.1016/0734-743x(94)80024-4. 
[4] Johnson, Gordon R., and Tim J. Holmquist. “An Improved Computational Constitutive Model for Brittle Materials.” AIP Conference Proceedings (1994). doi:10.1063/1.46199.

[5] Hwang, Hyeon-Jong, Sanghee Kim, and Thomas H.-K. Kang. "Energy-Based Penetration Model for Local Impact-Damaged Concrete Members.” ACI Structural Journal 114, no. 5 (September 2017). doi:10.14359/51689868.

[6] Rajput, Abhishek, R. Jakka, B.M. Pruthvik, and M.A. Iqbal. "Experimental Study of Plain and Reinforced Concrete Targets Subjected to Impact Loading.” Procedia Engineering 144 (2016): 124-131. doi:10.1016/j.proeng.2016.05.015.

[7] Iqbal, M.A., Abhishek Rajput, and P. Bhargava. "Plain and Reinforced Concrete Targets Subjected to Projectile Impact." Procedia Engineering 173 (2017): 138-144. doi:10.1016/j.proeng.2016.12.050.

[8] Xue, Y. L., D. G. Tang, W. X. Chen, Z. Z. Li, D. P. Li, and M. L. Yao. "Experimental and Analytical Study on the Penetration of Corundum-Rubble Concrete Subjected to Projectile Impact.” Shock and Vibration 2017 (2017): 1-10. doi:10.1155/2017/1396567.

[9] Smith, Jovanca, and Gianluca Cusatis. "Numerical Analysis of Projectile Penetration and Perforation of Plain and Fiber Reinforced Concrete Slabs.” International Journal for Numerical and Analytical Methods in Geomechanics 41, no. 3 (July 25, 2016): 315-337. doi:10.1002/nag.2555.

[10] Smith, Jovanca, and Gianluca Cusatis. "Numerical Analysis of Projectile Penetration and Perforation of Plain and Fiber Reinforced Concrete Slabs.” International Journal for Numerical and Analytical Methods in Geomechanics 41, no. 3 (July 25, 2016): 315-337. doi:10.1002/nag.2555.

[11] Tawadrous, Raed I., Walid A. Attia, and Mohamed Y. Laissy. "Using Ceramic Plates as Shielding for Concrete Blocks Against Projectile Penetration.” HBRC Journal 12, no. 3 (December 2016): 263-271. doi:10.1016/j.hbrcj.2014.11.011.

[12] Pereira, L.F., J. Weerheijm, and L.J. Sluys. "Simulation of Compaction and Crushing of Concrete in Ballistic Impact with a New Damage Model." International Journal of Impact Engineering 111 (January 2018): $208-221$. doi:10.1016/j.ijimpeng.2017.09.014.

[13] Tham, C.Y. "Reinforced Concrete Perforation and Penetration Simulation Using AUTODYN-3D." Finite Elements in Analysis and Design 41, no. 14 (August 2005): 1401-1410. doi:10.1016/j.finel.2004.08.003.

[14] Almusallam, Tarek, Yousef Al-Salloum, Saleh Alsayed, Rizwan Iqbal, and Husain Abbas. "Effect of CFRP Strengthening on the Response of RC Slabs to Hard Projectile Impact." Nuclear Engineering and Design 286 (May 2015): 211-226. doi:10.1016/j.nucengdes.2015.02.017.

[15] Pavlovic, A., and C. Fragassa. "Investigating the Resistance of Reinforced Barriers to High Velocity Projectiles." Engineering Structures 174 (November 2018): 384-395. doi:10.1016/j.engstruct.2018.07.074.

[16] Kamal, I.M., and E.M. Eltehewy. "Projectile Penetration of Reinforced Concrete Blocks: Test and Analysis." Theoretical and Applied Fracture Mechanics 60, no. 1 (August 2012): 31-37. doi:10.1016/j.tafmec.2012.06.005.

[17] Richardson, Alan, Kathryn Coventry, Thomas Lamb, and David Mackenzie. "The Addition of Synthetic Fibres to Concrete to Improve Impact/ballistic Toughness." Construction and Building Materials 121 (September 2016): 612-621. doi:10.1016/j.conbuildmat.2016.06.024.

[18] Rajput, Abhishek, and M.A. Iqbal. "Impact Behavior of Plain, Reinforced and Prestressed Concrete Targets." Materials \& Design 114 (January 2017): 459-474. doi:10.1016/j.matdes.2016.10.073.

[19] Kataoka, Shinnosuke, Masuhiro Beppu, Hiroyoshi Ichino, Tatsuya Mase, Tatsuya Nakada, and Ryo Matsuzawa. "Failure Behavior of Reinforced Concrete Slabs Subjected to Moderate-Velocity Impact by a Steel Projectile." International Journal of Protective Structures 8, no. 3 (September 2017): 384-406. doi:10.1177/2041419617721550.

[20] Lee, M., and Y.H. Yoo. “Analysis of Ceramic/metal Armour Systems.” International Journal of Impact Engineering 25, no. 9 (October 2001): 819-829. doi:10.1016/s0734-743x(01)00025-2.

[21] Kaibyshev, Rustam, Fanil Musin, Dmitry Gromov, T. ;G. Nieh, and Donald\&nbsp;R. Lesuer. "Effect of Cu and Zr Additions on the Superplastic Behavior of 6061 Aluminum Alloy.” MATERIALS TRANSACTIONS 43, no. 10 (2002): $2392-2399$. doi:10.2320/matertrans.43.2392.

[22] Christman, D. R., and J. W. Gehring. “Analysis of High - Velocity Projectile Penetration Mechanics.” Journal of Applied Physics 37, no. 4 (March 15, 1966): 1579 - 1587. doi:10.1063/1.1708570.

[23] Kennedy, R.P. "A Review of Procedures for the Analysis and Design of Concrete Structures to Resist Missile Impact Effects." Nuclear Engineering and Design 37, no. 2 (May 1976): 183-203. doi:10.1016/0029-5493(76)90015-7.

[24] National Research Council. Opportunities in protection materials science and technology for future army applications. National Academies Press, 2011. 
[25] LaSalvia, Jerry C., and James W. McCauley. "Inelastic Deformation Mechanisms and Damage in Structural Ceramics Subjected to High-Velocity Impact.” International Journal of Applied Ceramic Technology 7, no. 5 (February 16, 2010): 595-605. doi:10.1111/j.1744-7402.2010.02489.x.

[26] Wright, S.C., N.A. Fleck, and W.J. Stronge. "Ballistic Impact of polycarbonate-An Experimental Investigation.” International Journal of Impact Engineering 13, no. 1 (January 1993): 1-20. doi:10.1016/0734-743x(93)90105-g.

[27] Kumar, Sunil, Durga Shankar Gupta, Inderdeep Singh, and Apurbba Sharma. "Behavior of Kevlar/Epoxy Composite Plates under Ballistic Impact." Journal of Reinforced Plastics and Composites 29, no. 13 (September 8, 2009): 2048-2064. doi:10.1177/0731684409343727.

[28] Mohamed, Mamdouh E., Essam M. Eltehawy, Ismail M. Kamal, and Ahmed A. Aggour. "Experimental analysis of reinforced concrete panels penetration resistance." In Proceedings of the 13th International Conference on Aerospace Sciences and Aviation Technology. 2009. 